\title{
SEGMENTATION OF MICROSCOPIC IMAGES OF BACTERIA IN BULGARIAN YOGHURT BY TEMPLATE MATCHING
}

\author{
Zlatin Zlatev, Mariya Baeva, Petya Nikolova \\ Faculty of Technics and Technologies, Trakia University, Bulgaria \\ 38 Graf Ignatiev str., 8602 Yambol, Bulgaria \\ e-mail: zlatin.zlatev@trakia-uni.bg, viptbi_89@abv.bg, nikolova_pn@abv.bg
}

\begin{abstract}
The diagnosis of deviations in quality of yogurt is performed by approved methods set out in the Bulgarian national standard (BNS) and its adjacent regulations. The basic method of evaluation of the microbiological quality of the product is the microscopic. The method is subjective and requires significant processing time of the samples. The precision of diagnosis is not high and depends on the qualifications of the expert. The systems for pattern recognition in the most natural way interpret this specific expert activity. The aim of this report is to assess the possibility of application of a method of processing and image analysis for determination of the microbiological quality of yogurt. Selected method is template matching. A comparative analysis is made of the methods for template matching. The comparative analysis of available algorithms showed that the known ones have certain disadvantages associated with their rapid-action, the use of simplified procedures, they are sensitive to rotation of the object in the template. It is developed algorithm that complement these known and overcome some of their disadvantages.
\end{abstract}

Keywords: Yogurt, Bacteria, Template matching algorithm.

\section{INTRODUCTION}

The Bulgarian yogurt is fermented milk product by the action of yeast of Lactobacillus bulgaricus and Streptococcus thermophilus. The resulting product must contain live bacteria. In some countries rather than those fermented milks contain other bacteria [9].

For now, in our country the diagnosis of deviations in quality of yogurt is done by approved methods set out in Bulgarian national standard (BNS) and adjacent regulations. The basic method of evaluation of the microbiological quality of the product is the microscopic [23]. The evaluation of the microbiological quality of the yogurt is made by expert exclusively on the basis of visual assessments. The expert as a part of the rating methodology brings a subjective element depending on qualifications and experience, which makes technology irreproducible and relatively not sufficiently precise and effective.

The advantage of automated assessments, in which the human factor plays a minor role, is their objectivity, accuracy and performance. That is why the creation of effective automated technologies for assessing the quality of yogurt is an important and priority task.

The analysis of the recently published studies shows that for recognizing and determining the number of bacteria in biological products, the use of systems for receiving, processing and image analysis is important priority direction for the automatic determination of their specific characteristics. Explanation is that the systems for pattern recognition in the most natural way to interpret this particular expert activity [2, 3].

Creation of new and optimization of existing mathematical models and statistical methods, along with the realization of their algorithms for extraction, transformation and use of the information obtained in grading are the main areas in which work in the field of automated grading of dairy products. In automation, monitoring and management of these processes 


\section{ARTIL

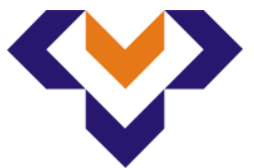 \\ Ipplied Reseirlches in Technicis, Technologies ind Bductition \\ Journal of the Faculty of Technics and Technologies, Trakia University https://sites.google.com/a/trakia-uni.bg/artte/}

require easy to use procedures relatively fast data processing, low requirements for technical realization of the developed systems $[2,4]$.

The aim of this report is to assess the possibility of application of a method of processing and analysis of images in determining the microbiological quality of yogurt.

\section{EXPOSURE}

The method for segmentation by template matching is one of the main, for the analysis and yield useful information about the practice from images. The techniques of this method are used in signal processing and pattern recognition to track objects, stereo vision, video compression, restoration of old photos [14].

In the method of segmenting by template matching, the belonging of the elements of the image to a certain image determines the degree of its matching with a rigid set of templates specified by the developer of the system [28]. The multitudes of representative points are formed most of the points located on the edges, contours and peaks of the corners of individual objects in the image because they bear the greatest information about its features. These characteristic points can be extracted from the source images in a variety of methods and algorithms, subject to various criteria.

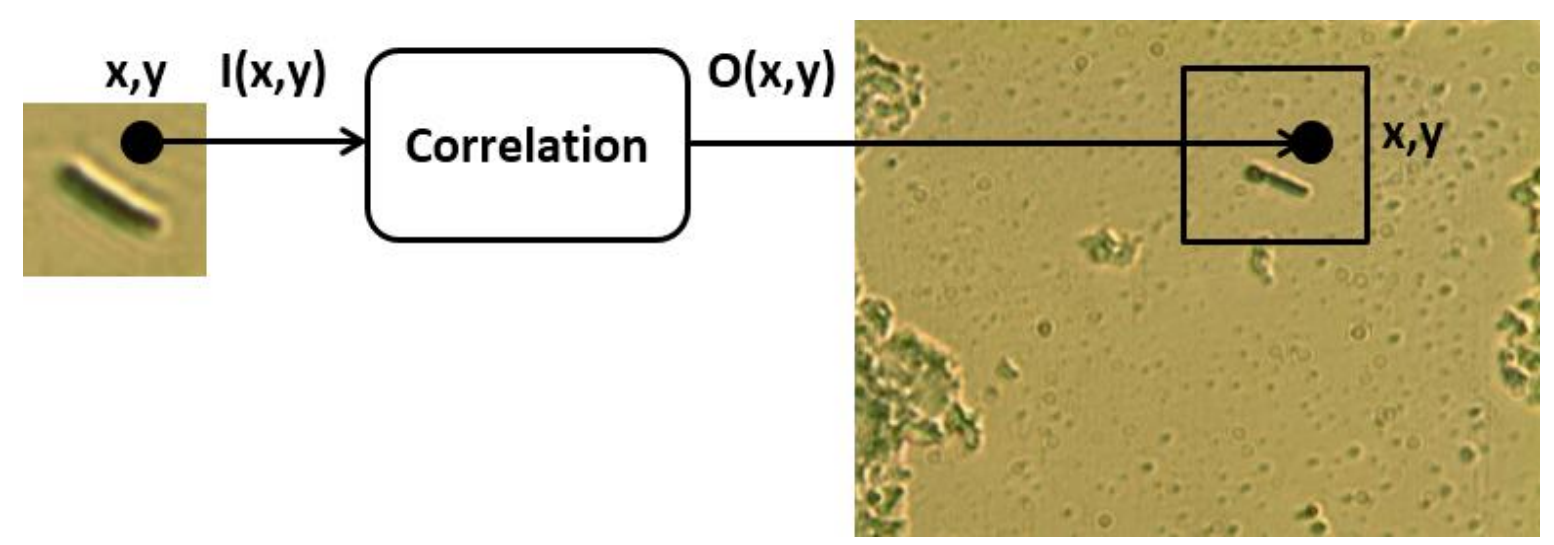

Figure 1. The principle of the search of template in image (Template matching)

Figure 1 shows the principle of the method of segmentation by template matching. In this method, image template of object is compared with all possible points from a source image and calculate a numeric index showing the coincidence of the template with some part of the image. The comparison is pixel by pixel.

The actuality of the problem of object recognition by template matching can be shown with the number of scientific publications and citations in this area [19].

Figure 2 illustrates the relationship between the number of publications and citations of this when searching the Internet database ScienceDirect by keyword "template matching". Besides the large number of publications in recent years (2012-2016) reached more than 7000 , the number citations in this area also increases. The correlation between these two indicators is above 0.8 . This shows that the presented method is actively used for object recognition in images. 


\section{IRTIIL $<>$}

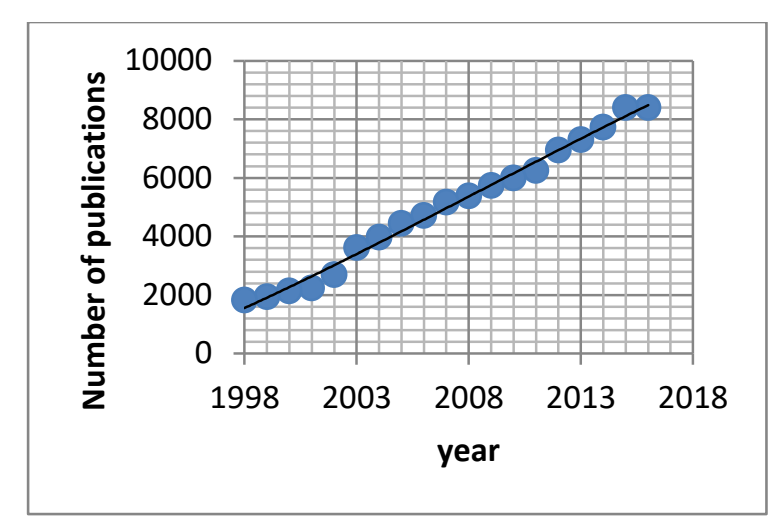

a) number of publications
Ipplied Researlohes in Technics, Technologies and Bductition

Journal of the Faculty of Technics and Technologies, Trakia University https://sites.google.com/a/trakia-uni.bg/artte/

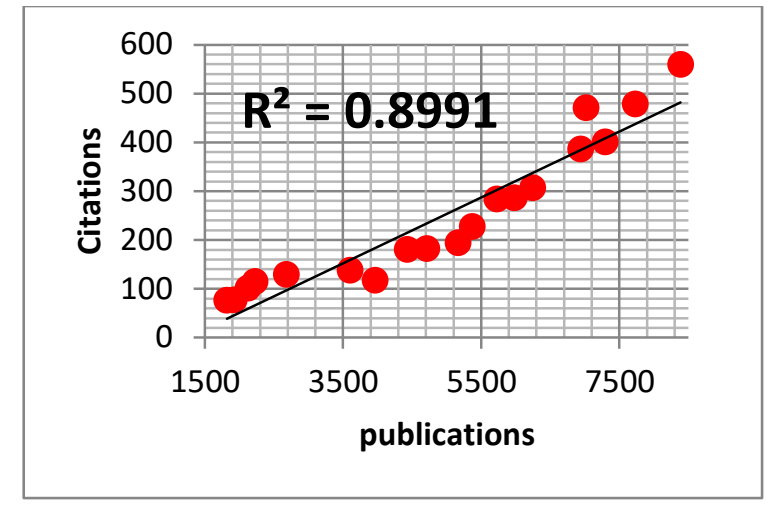

b) correlation between publications and citations

Figure 2. Search results in ScienceDirect by keyword "template matching"

The problem of the search comes down to choice or synthesis of criterion for similarity and calculate its estimates and therefore quickly appear different search algorithms. The search is often placed in aggravating circumstances when the image is subjected to disturbing effects it as linear or nonlinear distortion, shifts, rotations, zoom and more. The real problem, however, comes from the fact that, in general, need to look no small template in quite large picture, which means that digital data that must be processed become too large in volume and many algorithms do not work in practice because of the large time required to perform the calculations. Thus arises a new problem - fast-action of the algorithms.

One of the main approaches to increase the speed of calculation is appropriate to reduce the volume of non-essential information [24]. The use of the method for segmenting of images using template matching for pattern recognition and counting the bacteria is appropriate when subjects have some similarities. The templates also need to provide the full range of options for the type, spatial, color, texture, the distance between them. The method is suitable for use when detected objects have relatively many differences between them.

Shimada et al [20] used a slightly different approach. They use the method of segmentation with template matching by using three-dimensional images obtained by grouping the twodimensional ones. The method is used for counting nuclei in the cells recognized by voxels (three-dimensional equivalents of the pixels) which are used as templates.

Kothari et al [12] used for the same purpose spherical templates.

The advances in biotechnology led to the need to adapt the microbiological techniques in many fields of applied biology. "Color-Pro" software has functions that can be used for counting of bacterial colonies. Various parameters of the colony as intensity, size, shape, connectivity and color image can be determined in colony count.

Young et al [26] offer a solution to some issues arising from the use of the method of template matching in identifying the bacteria in microscopic images with differential interference contrast. The use of such images is complicated from a technical standpoint because of the way in which light affects the final image. Other problems in these images are different sizes and orientation of cells. Proposed by the authors method compensates these problems.

Miroslaw et al [15] used correlation methods for automatic detection of mitotic cells. These are the cells, split into two separate cores, but with identical chromosomes. The receipt of color digital images is by a camera attached to the eyepiece of a microscope. Since the recognized cells are identical in shape and form and they are uniform, the authors have preferred method for segmenting by template matching. The templates are derived from

IRTIIE Vol. 4, No. 3, 2016 ISSN 1314-8788 (print), ISSN 1314-8796 (online), doi: 10.15547/artte.2016.03.008 


\section{ARTTE $Y$}

Ipplied Researl ches in Technics, Technologies ind Rduration

Journal of the Faculty of Technics and Technologies, Trakia University https://sites.google.com/a/trakia-uni.bg/artte/

three-dimensional data model. Then honed by the test images. Three-dimensional models differ depending on the type of cells. For example, in one type of cell as a template has been used black circle with a white brim, while others circle is white and the periphery - black.

In his dissertation work Elshenawy [7] develops automatic image processing system to process and analyze embryo microscopic images by detecting cells in embryos and compares their properties as criteria is reimplantation. The main problem is the overlapping of the cells in the images, another disadvantage is the brightness and dimensions which vary within wide ranges. These problems are affected in the development of recognition algorithm. After define the perimeter of the embryo are applied several techniques to separate the edges - Sobel, Prewitt and Canny as preliminary operations for applying Hough transformation. Out of 94 are identified only 62 cells (65\%). These poor results prompted the author to apply the method for segmentation by template matching using several different templates of different sizes as defined criterion by which to choose size, suitable for detection of objects studied. Used is the sum of absolute difference (SAD) and a normalized cross-correlation (NCC). The author reports that the second method gives better results than the first of the studied sites. Recognition accuracy was increased to $80 \%$.

\section{MATERIAL AND METHODS}

Object of the survey are color digital images of micro-samples of yogurt. Subject to the study is the detection and enumeration of bacteria of the genus Lactobacillus in digital images. Micro-morphological characterization shows that dominate short, but there also are longer sticks. The location of the bacteria is in single formation, in pairs or in short chains. The observed morphology and the criteria by which is performed their selection shows their possible belonging to the genus Lactobacillus.

The laboratory staging for capturing and analyzing of images include personal computer, microscope, camera and software for processing of data, is described in detail in [27].

Methods and tools of Matlab Statistics Toolbox and Data Analysis Toolpack of MS Excel are used in order to processing, analysis and visualization of data and results of this work.

The collection, processing and analysis of images can be realized through various programming languages and software environments such as $\mathrm{C}, \mathrm{C}++$, Java.

A programming platform Matlab is selected because it provides a programming language for high-level, interactive development environment algorithms, data visualization, data analysis calculations. Matlab is used in many areas such as signal processing, imaging, spectral characteristics, study of automatic control systems. There are many toll boxes containing built-in functions, including libraries for image processing. Vector and matrix operations are supported that are crucial in engineering calculations and image processing. This programming environment provides rapid development of algorithms that focus the user on solved problem, not in the details of the program code.

\section{METHODS FOR SEGMENTATION BY TEMPLATE MATCHING}

Basic methods for pattern recognition by template matching and their mathematical description are presented in Table 1. In formulas involved the main image $f$ and the template $\mathrm{t}$, described by their pixels.

In addition to these basic methods in practice are used variants or combinations of different methods. For example, correlation and fast Fourier transform; correlation and inverse Fourier transform.

In Table 2 the advantages and disadvantages of using of methods for segmentation by template matching are given. The next is short description of each method separately. 
Table 1. Basic methods for template matching

\begin{tabular}{|l|c|}
\hline \multicolumn{1}{|c|}{ Method } & Mathematical description \\
\hline Correlation & $c(x, y)=\sum_{k=-W}^{W} \sum_{l=-H}^{H} f(x+k, y+l) t(k, l)$ \\
\hline Normed Correlation & $c(x, y)=\frac{\sum_{x, y}[f(x, y)-\bar{f}][t(x, y)-\bar{t}]}{\left(\sum_{x, y}[f(x, y)-\bar{f}]^{2} \sum_{x, y}[t(x, y)-\bar{t}]^{2}\right)^{1 / 2}}$ \\
\hline Maximum Absolute Differences MAD & $d_{\infty}\left(f_{j}, t\right)=\lim _{x \rightarrow \infty} \sum_{i=1}^{n}\left|f_{i, j}-t_{i}\right|^{p}$ \\
\hline Sum of the Absolute Difference SAD & $c(x, y)=\sum_{k=-W}^{W} \sum_{l=-H}^{H}|f(x+k, y+l)-t(k, l)|$ \\
\hline Sum of the Squared Difference & $c(x, y)=\sum_{k=-W}^{W} \sum_{l=-H}^{H}[f(x+k, y+l)-t(k, l)]^{2}$ \\
\hline
\end{tabular}

Table 2. Advantages and disadvantages of methods for template matching

\begin{tabular}{|c|c|c|c|}
\hline Method & Advantages & Disadvantages & Ref. \\
\hline Correlation (Corr) & $\begin{array}{l}\text { Reliable and easy to } \\
\text { understand criterion }\end{array}$ & $\begin{array}{l}\text { It requires large computational } \\
\text { resources and is sensitive to light and } \\
\text { noise in the image }\end{array}$ & {$[1,17]$} \\
\hline $\begin{array}{l}\text { Normed } \\
\text { Correlation (NCC) }\end{array}$ & $\begin{array}{l}\text { Reliable and easy to } \\
\text { understand criterion }\end{array}$ & Requires large computational resources & [1] \\
\hline $\begin{array}{l}\text { Maximum } \\
\text { Absolute } \\
\text { Differences (MAD) }\end{array}$ & Resistant to noise & Slow method & [17] \\
\hline $\begin{array}{l}\text { Sum of the } \\
\text { Absolute } \\
\text { Difference (SAD) }\end{array}$ & $\begin{array}{l}\text { Use of simplified operations. } \\
\text { Facilitated analysis of results }\end{array}$ & $\begin{array}{l}\text { It may be unreliable due to the effect of } \\
\text { contextual factors such as changes in } \\
\text { lighting, color, direction, size or shape }\end{array}$ & [17] \\
\hline $\begin{array}{l}\text { Sum of the } \\
\text { Squared Difference } \\
\text { (SSD) }\end{array}$ & $\begin{array}{l}\text { A widely used method with } \\
\text { simplified calculation } \\
\text { procedures }\end{array}$ & $\begin{array}{l}\text { Sensitive to changes of light and image } \\
\text { noise }\end{array}$ & [8] \\
\hline $\begin{array}{l}\text { Fourier Methods } \\
\text { (FFT) }\end{array}$ & $\begin{array}{l}\text { It is resistant to highly } \\
\text { correlated frequency- } \\
\text { dependent disturbances }\end{array}$ & Slow operation of the algorithm & $\begin{array}{c}{[1,8,10} \\
]\end{array}$ \\
\hline Convolution (Conv) & $\begin{array}{l}\text { Simple, but secure algorithm } \\
\text { for recognition }\end{array}$ & One of the slowest methods & [11] \\
\hline $\begin{array}{l}\text { Zero Mean } \\
\text { normalized cross } \\
\text { correlation (ZNCC) }\end{array}$ & $\begin{array}{l}\text { Significantly reduces } \\
\text { computation time }\end{array}$ & Requires large computational resources & [6] \\
\hline $\begin{array}{l}\text { Optimized Sum of } \\
\text { Absolute } \\
\text { Difference (OSAD) }\end{array}$ & $\begin{array}{l}\text { Unaffected by the light and the } \\
\text { angle of rotation of the object } \\
\text { in the template }\end{array}$ & Influenced by the background image & [8] \\
\hline $\begin{array}{l}\text { Optimized Sum of } \\
\text { Squared Difference } \\
\text { (OSSD) }\end{array}$ & $\begin{array}{l}\text { Unaffected by the light and the } \\
\text { angle of rotation of the object } \\
\text { in the template }\end{array}$ & Influenced by the background image & [8] \\
\hline $\begin{array}{l}\text { Pyramid sum of } \\
\text { absolute difference } \\
\text { (PSAD) }\end{array}$ & $\begin{array}{l}\text { Reduces computation time and } \\
\text { improves recognition accuracy }\end{array}$ & Not used directly for recognition & [11] \\
\hline $\begin{array}{l}\text { Sum of Hamming } \\
\text { Distance (SHD) }\end{array}$ & $\begin{array}{l}\text { Used primarily to determine } \\
\text { the difference between signals }\end{array}$ & Not used directly for recognition & {$[6,8]$} \\
\hline $\begin{array}{l}\text { Asymmetric } \\
\text { correlation (ASC) }\end{array}$ & Is not affected by noises & Slow method & [1] \\
\hline
\end{tabular}

IRTIIE Vol. 4, No. 3, 2016 ISSN 1314-8788 (print), ISSN 1314-8796 (online), doi: 10.15547/artte.2016.03.008 


\section{ARTTIE $Y$}

Ipplied Researl ches in Technics, Technologies ind Rduration

Journal of the Faculty of Technics and Technologies, Trakia University https://sites.google.com/a/trakia-uni.bg/artte/

Correlation (Corr). In the task of detection of a reference fragment in the image using a ratio of the normalized cross-correlation, the correlation is used as a measure for evaluating the degree of similarity. This classic and reliable criterion for assessing the similarity is quite labor intensive, so in terms of high speed requirements up to date problem in search capabilities, allowing to reduce the number of computational operations [18].

Normalized correlation (NCC). Using correlation to recognize from a Template has the main disadvantage that the process can't take place in the presence of different lighting and image noise. Normalization consists of amending the intensity of the image and pattern size. A disadvantage of the method is that it requires large computational resources.

Sum of absolute difference (SAD). SAD is a sum of all the absolute values between the pixels of the image from which is sought with template. Since it applies only addition and subtraction may be applied not complicated operations. The small amounts of SAD indicate a high degree of match between the template and the main image. In full match the difference is 0 [1].

Sum of squared differences (SSD). SSD is probably the most popular method of measuring distance, including recognition from a Template, with good mathematical properties and efficient computational schemes. The method is sensitive to the change of light and image noise [5].

Maximum absolute difference (MAD). Metrics defined by MAD is a specified distance. Also, this method calculates the best position of the template [a22].

Fast Fourier Transform (FFT). In order to increase the speed of computation due to the different conditions that produce images, they have a noise which depends on the spectrum. In this case, preferred are the methods based on Fourier transform, instead of correlation methods. The image is presented in the frequency domain. Use a method for phase correlation based on the theorem of the Fourier shift. Calculated is the crossing spectra of both images and a peak is determined. The method is suitable for highly correlated frequency-dependent noise. Also, the method is suitable for processing large images as it requires less time for calculation [8].

Method by convolution (Conv). The method involves simple but fast algorithm for recognition from a template based on the correlation. The calculation of the correlation coefficient becomes with convolution. The goal is to find the limit of the Region of Interest (ROI) in the image. Using convolution increases the processing speed. This method is easy to understand, but it is one of the slowest [6].

Zero mean normalized cross-correlation (ZNCC). The method finds an optimal solution in the process of full search and this leads to a significant reduction of the computation time. The algorithm is a generalization of the technique boundary partial correlation. ZNCC offers an effective comparison of the template with the main image. It has a better performance compared to the NCC. It requires more productive computers, but significantly accelerates the identification [8].

Optimum sum of absolute differences (OSAD). The method is better compared to the NCC. It is not influenced by the darkness of the image, but on the other hand is influenced by changes in the background, for example in the case of objects that are not of interest for recognition. This leads to increase of the wrong detected objects [11].

Optimum sum of the squares of the differences (OSSD). As with OSAD, OSSD method is not affected by the lighting of the picture, but again influenced by the type of background and existing objects in it. Do not depend on the angle of rotation of the object in the template. The method is $3 \%$ more productive compared to OSAD. In modern stage are carried investigations into improve the performance of the algorithm in order to overcome the problems of the influence of the background [17]. 


\section{ARTIIE

Pyramid sum of absolute difference (PSAD). The function is not used directly for recognition. The purpose of its use is accelerating the computing process. It affects the overall performance of the main algorithm reduces computation time and improves recognition accuracy. It is especially suitable for images with noise. Using this feature also serves to exclude areas of the main image, are not relevant for recognition. It is suitable mainly in cases where the template and the main image have not degradation [6].

Sum of Hamming distances (SHD). The method has a low coefficient of location and calculates distance between the strings, instead of between matrices. Used primarily to determine the difference between signals [11].

Asymmetric correlation (ASC). The asymmetric Correlation function is sensitive to light of the image, but is resistant to the noises. It correlates with irregular pattern normalized version of each window from the main image in the frequency domain. The function is much more stable compared to the direct use of correlation coefficients. The direct use of asymmetric correlation is a slow process as the discrete Fourier transform is calculated for each window separately. To speed up the calculation process are developed algorithms working in the time domain and discrete Fast Fourier Transform is calculated only for windows for which it is necessary [8].

\section{ALGORITHMS FOR SEGMENTATION BY TEMPLATE MATCHING}

Algorithms for recognition by template matching are selected, that are readily available on the Internet and use basic methods as Corr, NCC, FFT etc. [13, 22]. The algorithms are used in their original form without modification. A description of the selected algorithms is made, as well as a comparative analysis by which can be determined their effectiveness.

Algorithm (A1). In algorithm 1 is used function normxcorr2 for normalized cross-correlation between matrices. An area with maximum correlation is Detected and the results are displayed graphically. In the algorithm is used B color components from RGB color model rather than as in most known ones that use levels of gray.

Figure 3 presents the performance of the algorithm 1. Appears main image, template and part of the main image, where the object is detected with the highest correlation with the template.

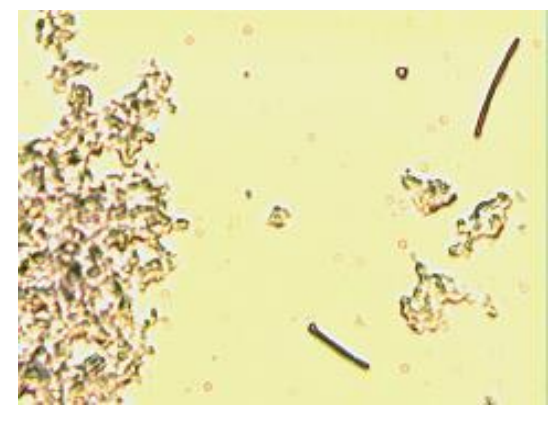

a) main image

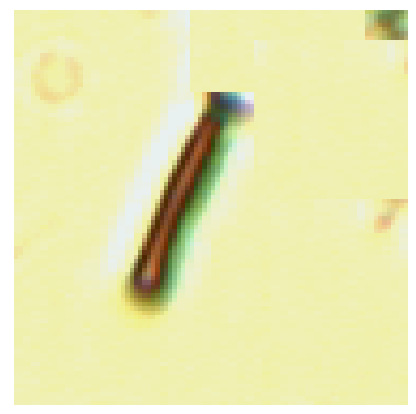

b) template

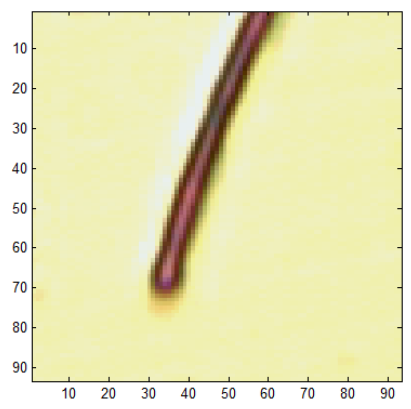

c) results of work of the algorithm

Figure 3. A work result of the algorithm 1

Algorithm 2 (A2). In the creation of the second algorithm, the authors use two transformations of images - In levels of gray and then to binary. Here is used a combination of Fourier transform and calculation of correlation. Operations to determine the size of the frame to be fenced the recognized object have only presentational character.

IRTIIE Vol. 4, No. 3, 2016 ISSN 1314-8788 (print), ISSN 1314-8796 (online), doi: 10.15547/artte.2016.03.008 


\section{ARTITE \\ $Y$ \\ Ipplied Reseirlches in Technicis, Technologies ind Bductition \\ Journal of the Faculty of Technics and Technologies, Trakia University https://sites.google.com/a/trakia-uni.bg/artte/}

Figure 4 shows the performance of algorithm 2. The objects and template are visualized. It is presented three-dimensional graphics on correlations in different parts of the main image with the template. Finally has been observed the main image, conversion to black and white and the recognized object.

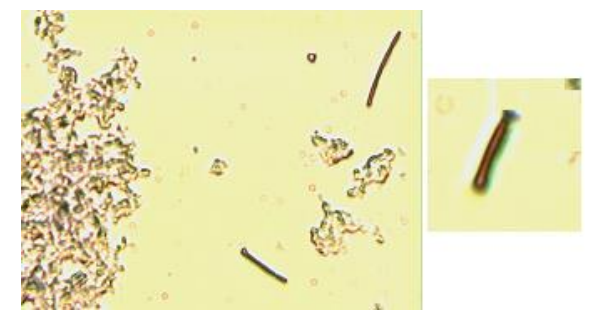

a) main image and template

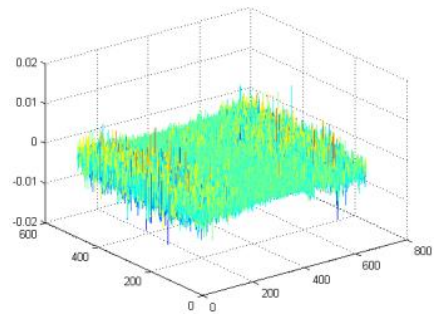

b) correlation between the image and template

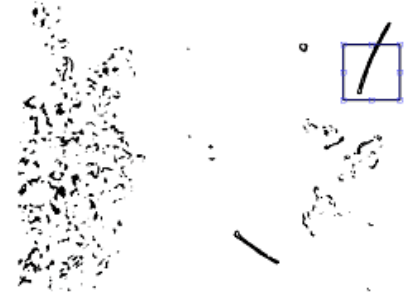

c) results of work of the algorithm

Figure 4. A work result of the algorithm 2

Algorithm 3 (A3). As with the first algorithm in the algorithm 3 is used $B$ (RGB) color component. The typical here is that it is drawn a correlation matrix by two nested loops of type For-End. The correlation function is calculated by corr2 unlike the first algorithm, which uses the normalized correlation.

Figure 5 presents the results of work of algorithm 3. By function "Colorbar" is displayed the correlation in all primary image with template. Then is displayed the template and finally the recognized object on the main image represented in its $B(R G B)$ color component.

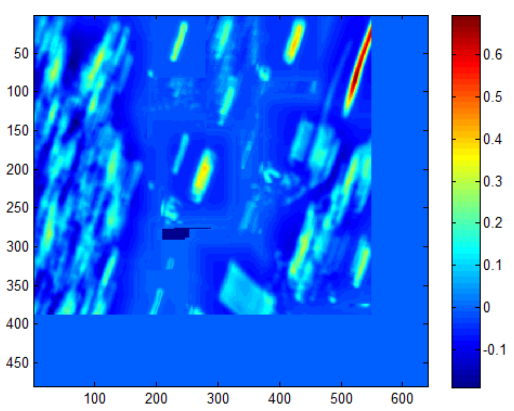

a) calculation of correlation

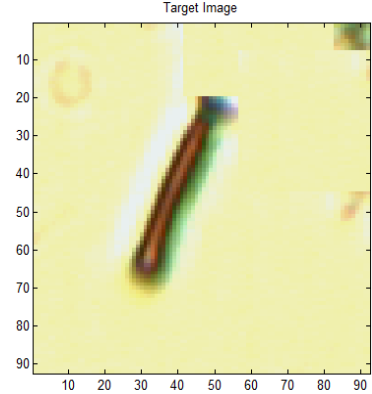

b) visualization of the template

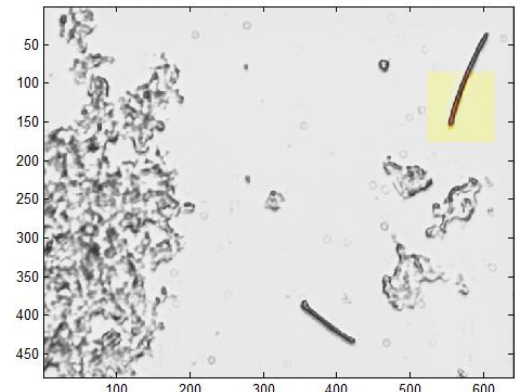

c) results of work of the algorithm

Figure 5. A work result of the algorithm 3

Algorithm 4 (A4). In algorithm 4 is used again the $B(R G B)$ color component. The images are presented as signals. It is implemented Fourier transform. After conversion the results are normalized and it determines the peak value in the result.

Figure 6 presents the performance of algorithm 4. Displayed are the main image and the template. Appears correlation in the entire image with template using the same functions for presentation as in algorithm 3, but here the color scheme is gray, realized by function colormap (gray). Finally is displayed portion of the main image by superimposed on its template. 


\section{IRTTE}

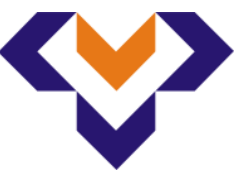

Ipplied Resseirl hes in Teednicis, Technologies and Educration

Journal of the Faculty of Technics and Technologies, Trakia University https://sites.google.com/a/trakia-uni.bg/artte/
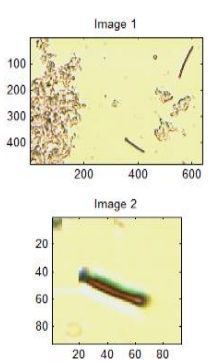

a) visualization of the image and template
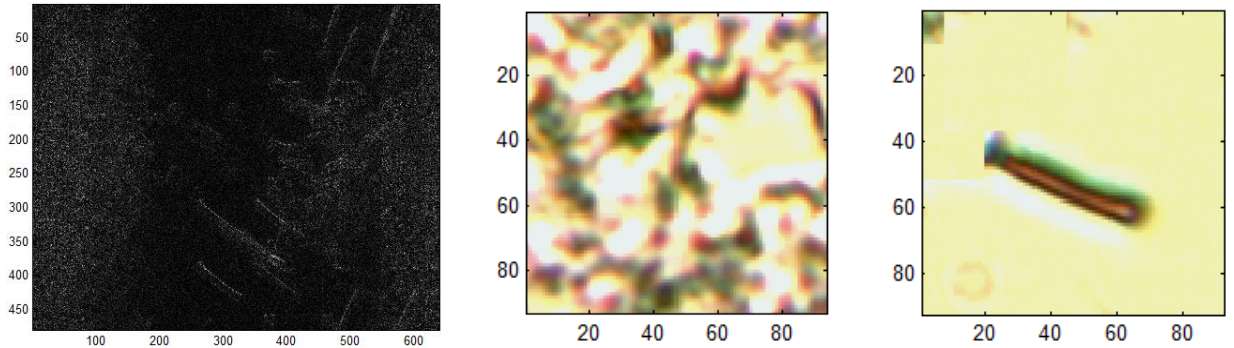

b) calculation of the correlation c) results of work of the algorithm

Figure 6. A work result of the algorithm 4

Algorithm (A5). Algorithm 5 use function of normalized cross-correlation as the first A1. The difference consisted in the fact that the images are converted to gray, and then into binary, and not as in the first, third and fourth algorithms using color components.

Figure 7 shows the performance of the algorithm 5 . Here the authors of algorithm preferred putting the results on a common graphic screen. Displayed are the main image and the background converted to black and white. The correlation is presented in levels of gray. Finally, is presented the main image with template affixed on the recognized object.
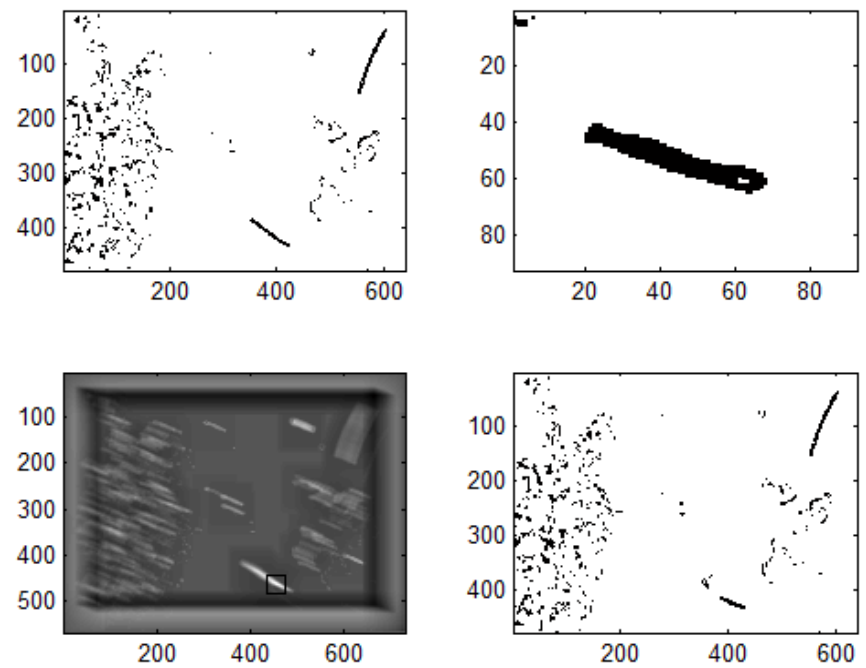

Figure 7. A work result of the algorithm 5

Algorithm 6 (A6). Algorithm 6 uses the same functions as in algorithm 4. The difference is in the use of the conversion of the images to grayscale and then into binary. Added features highlight the recognized object that again as with other algorithms have only a presentational character.

Figure 8 presents the performance of the algorithm 6 . The correlation between various points of the image and the template is provided on the three-dimensional graphics. Displayed is a rectangle on the recognized object. Finally, it is presented a two-dimensional graph of the correlation. 


\section{ARTTIE $Y$}

Ipplied Resseirthes in Teednics, Technologies and Educration Journal of the Faculty of Technics and Technologies, Trakia University https://sites.google.com/a/trakia-uni.bg/artte/

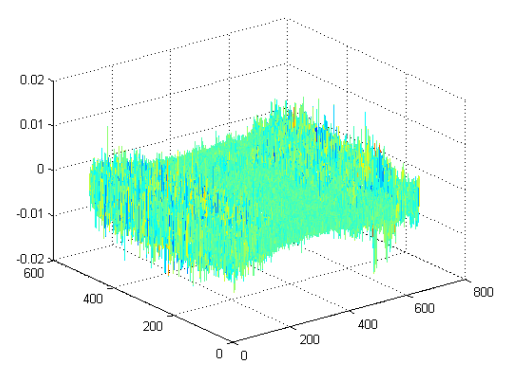

a) calculation of the correlation

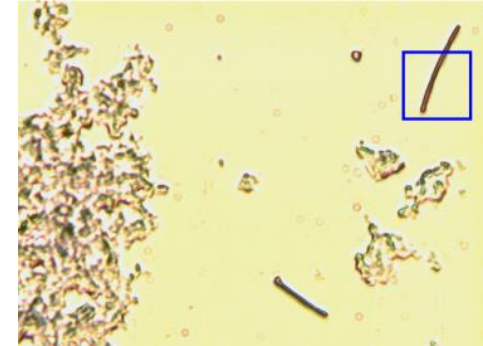

b) visualization of the image and recognized object

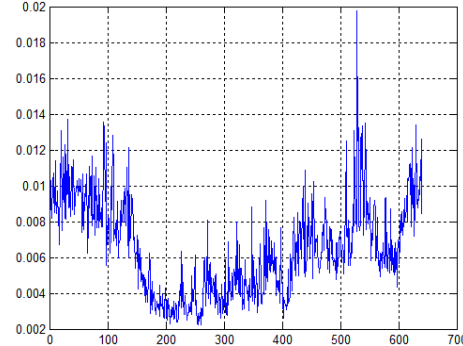

c) correlation in two dimensional coordinate system

Figure 8. A work result of the algorithm 6

In summary it can be said that some of the submitted algorithms are used color components and other conversion into grayscale. The latter is the preferred method for image processing, but It has some drawbacks.

Conversion to grayscale requires mathematical apparatus that has multiple options for decision. Not all manufacturers of software tools provide information on what functions for conversion into levels of gray are used in their products.

The transformation of the image into binary, regardless of the manner of processing facilities and the smaller the necessary computational resources also have some disadvantages. In this transformation, determining which pixels will be white and black which depends on the threshold of binarization.

The use of loops of the type For-End, and the nested loops of this type considerably increase the time for processing the data.

Each algorithm has its advantages and disadvantages. Some are more reliable than others. Third are easier to analyze mathematically. The choice of algorithm is a decision that may be influenced from many factors. The algorithm must meet several criteria. Examples of such criteria are: What will be used? How easy and convenient it is the use of the algorithm? What load can bear the resources of the computer system? [16, 21, 25].

Table 3. Analysis of Algorithms

\begin{tabular}{|l|c|c|c|c|c|c|}
\hline \multicolumn{1}{|c|}{ Algorithm } & A1 & A2 & A3 & A4 & A5 & A6 \\
\hline Number of operations, Number & 125 & 295 & 191 & 97 & 119 & 175 \\
\hline Maximum number of calls to an operation, Number & 9 & 36 & 251028 & 14 & 7 & 16 \\
\hline $\begin{array}{l}\text { Sensitivity to rotation of the object in the template, } \\
\text { Yes/No }\end{array}$ & No & No & No & No & Yes & No \\
\hline Use of color components, Yes/No & Yes & No & Yes & Yes & No & No \\
\hline Use of For-End loop in the main program, Yes/No & No & No & Yes & No & No & Yes \\
\hline Nested loops in the main program, Yes/No & No & No & Yes & No & No & No \\
\hline Used method, Method & NCC & FFT & Corr & FFT & NCC & FFT \\
\hline Graphical visualization of the results, Yes/No & Yes & Yes & Yes & Yes & Yes & Yes \\
\hline
\end{tabular}

Table 3 presents the results of the analysis of the selected algorithms. The number of operations in the algorithm are within 97 to 295 while the number calls move in much wider range. This is due to the use of loops of type For-End in the main program. Of particular importance is the problem with using nested loops. For example, in algorithm 3 it causes an increase in the number of calls to a single operation to 251028. Another disadvantage of this algorithm is to use the basic function of correlation Corr, whose problems have been 


\section{IRTTIE}

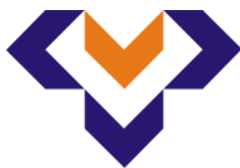

Ipplied Reseertrches in Technics, Technologies and Bduration

Journal of the Faculty of Technics and Technologies, Trakia University https://sites.google.com/a/trakia-uni.bg/artte/

discussed in previous sections of this work. In the other 5 algorithms the number of calls to an operation is up to 7-36. The number of operations performed visibly does not affect the other characteristics of the algorithm, but it must be proven by determining the time for execution of various algorithms.

In the available literature [8] states that in addition to the elements of the algorithm on its performance affects the size of the used template.

Figure 9 and Table 4 presents the results of the time of recognition of bacteria depending on the image size of the used templates. It is seen that the size of the template affects a significant impact on the execution time of various algorithms. It is seen that in the algorithms that use the loop of type For-End, the processing time is greater than the other. Such algorithms are 3 and 6.

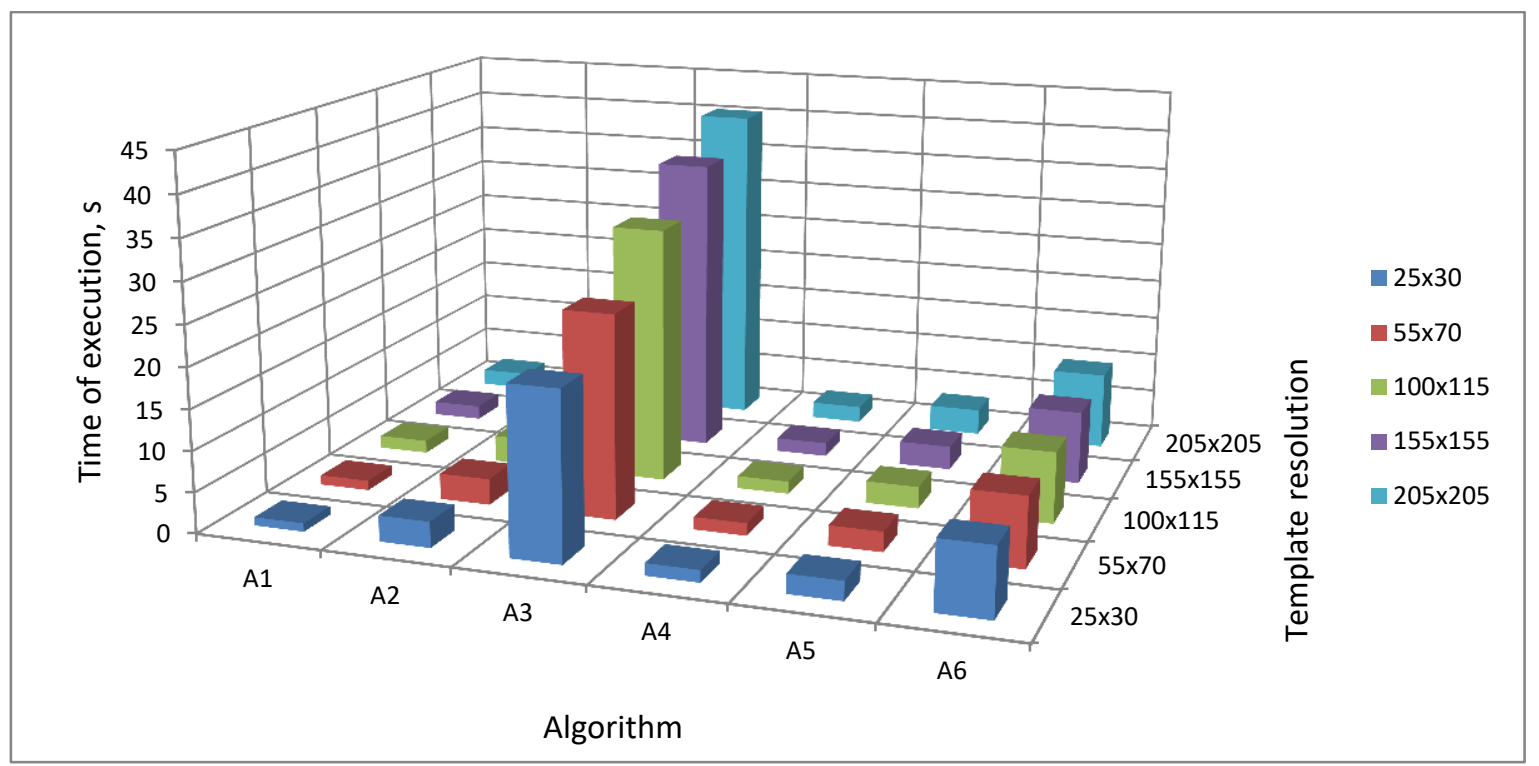

Figure 9. Execution time of the algorithm depending on the size of the template

Table 4. Execution time of algorithm depending on the size of the template

\begin{tabular}{|c|c|c|c|c|c|}
\hline \multirow{2}{*}{ Tlgorithm } & $\mathbf{2 5 x 3 0}$ & $\mathbf{5 5 x 7 0}$ & $\mathbf{1 0 0 \times 1 1 5}$ & $\mathbf{1 5 5 x 1 5 5}$ & $\mathbf{2 0 5 \times 2 0 5}$ \\
\cline { 2 - 6 } & \multicolumn{5}{|c|}{ Execution Time, s } \\
\hline A1 & 1,03 & 1,20 & 1,58 & 1,73 & 2,04 \\
\hline A2 & 3,16 & 3,21 & 3,29 & 3,69 & 3,79 \\
\hline A3 & 20,49 & 25,02 & 31,59 & 36,63 & 40,35 \\
\hline A4 & 1,49 & 1,54 & 1,55 & 1,69 & 2,04 \\
\hline A5 & 2,34 & 2,47 & 2,71 & 2,95 & 3,23 \\
\hline A6 & 8,38 & 8,63 & 8,81 & 9,06 & 9,56 \\
\hline
\end{tabular}

Table 5 presents the results of two-factor analysis of variance, which determines whether the execution time depends on the algorithm used. The value obtained at the level of significance $p<<0,05$ with a margin of error $\varepsilon=0,05$ shows that the impact on performance of the algorithm has a the number of calls to one operation. This number is the greatest in Algorithms 3 and 6, which are also as stated above using loops of the type For-End and nested ones. 
Table 5. Results from two-factor Analysis of variance (ANOVA)

\begin{tabular}{|c|c|c|c|c|c|c|}
\hline \multicolumn{7}{|c|}{ Anova: Two-Factor Without Replication } \\
\hline SUMMARY & Count & Sum & \multicolumn{2}{|c|}{ Average } & \multicolumn{2}{|c|}{ Variance } \\
\hline A1 & 5,00 & 7,58 & & 1,52 & & 0,17 \\
\hline $\mathrm{A} 2$ & 5,00 & 17,14 & & 3,43 & & 0,08 \\
\hline A3 & 5,00 & 154,08 & & 30,82 & & 66,38 \\
\hline A4 & 5,00 & 8,31 & & 1,66 & & 0,05 \\
\hline A5 & 5,00 & 13,70 & & 2,74 & & 0,13 \\
\hline A6 & 5,00 & 44,44 & & 8,89 & & 0,20 \\
\hline $25 \times 30$ & 6,00 & 36,89 & & 6,15 & & 56,40 \\
\hline $55 \times 70$ & 6,00 & 42,07 & & 7,01 & & 85,14 \\
\hline $100 \times 115$ & 6,00 & 49,53 & & 8,26 & & 137,95 \\
\hline $155 \times 155$ & 6,00 & 55,75 & & 9,29 & & 186,80 \\
\hline $205 \times 205$ & 6,00 & 61,01 & & 10,17 & & 226,45 \\
\hline Source of Variation & SS & $d f$ & MS & $F$ & P-value & F crit \\
\hline Rows & 3259,79 & 5,00 & 651,96 & 63,94 & 0,00 & 2,71 \\
\hline Columns & 64,12 & 4,00 & 16,03 & 1,57 & 0,22 & 2,87 \\
\hline Error & 203,92 & 20,00 & 10,20 & & & \\
\hline Total & 3527,84 & 29,00 & & & & \\
\hline
\end{tabular}

The same results were obtained when determining the correlation between the execution time of the algorithms and the number of operations. In the above initial conditions and set criteria is established correlation above 0,95 between execution time and the number calls to a single operation (Table 6).

Table 6. Correlation between execution time and number of operations in the algorithm

\begin{tabular}{|l|c|c|c|}
\hline & Number of operations & $\begin{array}{c}\text { Maximum number of calls } \\
\text { to an operation }\end{array}$ & Time of execution \\
\hline Number of operations & 1 & & \\
\hline $\begin{array}{l}\text { Maximum number of calls } \\
\text { to an operation }\end{array}$ & 0,16 & 1 & \\
\hline Time of execution & 0,23 & 0,97 & 1 \\
\hline
\end{tabular}

Development of algorithm for simultaneous recognition and counting of bacteria in microscopic images of yogurt. From the comparative analysis of basic recognition algorithms for segmentation using the method template matching is established that the to recognize of bacteria in yogurt is appropriate to use algorithms using color components, Fourier transformation and that not use nested loops.

Suitable for developing the algorithm for practical application of automated recognition and enumeration of bacteria in yogurt is algorithm 4. At its base are created software tools for recognizing and enumeration of bacteria by template.

The developed algorithm is implemented in the following sequence:

$>$ Read the main image and the template;

Extract $\mathrm{B}(\mathrm{RGB})$ color components of the main image and the template;

$>$ Visualizing the two images;

$>$ Applying the Fourier transform of both images and presentation as signals;

$>$ Multiply the signal of the main image with complex transformations of the template;

Valuation of the results;

$>$ Applying the Inverse Fourier transformation;

$>$ Determination of the maximum value;

$>$ Determination of the position in the image, in which the maximum value;

$>$ Visualization of results. 


\section{ARTTL $Y$}

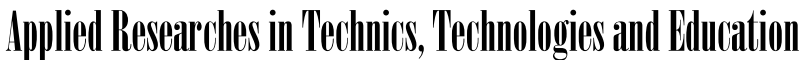
Journal of the Faculty of Technics and Technologies, Trakia University https://sites.google.com/a/trakia-uni.bg/artte/

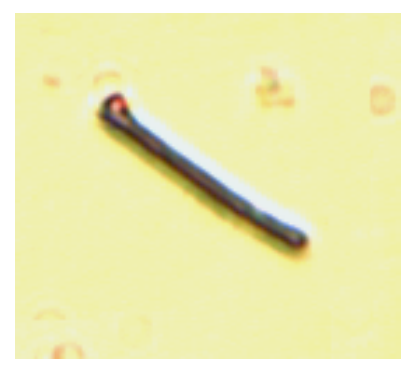

a) template

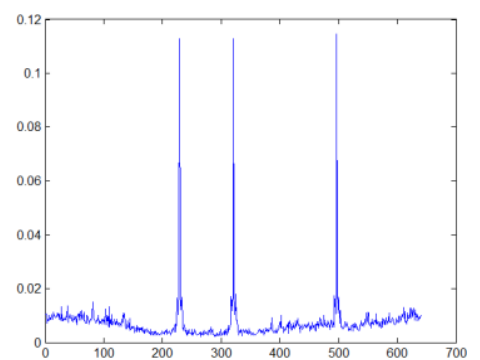

b) correlation in two dimensional coordinate system

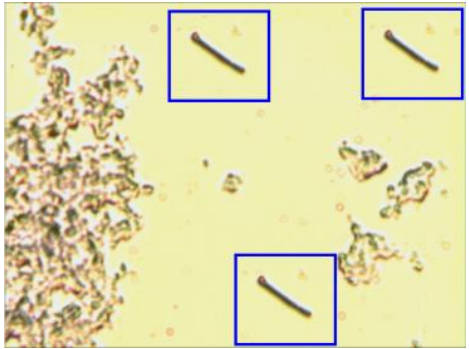

c) visualization of the recognized objects

Figure 10. The results of the developed algorithm

Figure 10 is an example of the work of developed algorithm for recognition by template matching. It is seen that can be recognized all bacteria in the image. Even in poorly prepared sample, as observed on the picture has large areas with yogurt. The total execution time of the algorithm is $10,23 \mathrm{~s}$. The operations are 215 . The maximum number of calls to an operation is 200 times, and minimum 2. For the calculations are used 25 basic variables.

\section{CONCLUSION}

The diagnosis of deviations in quality of yoghurt in Bulgaria is carried out by established methodologies defined by Bulgarian national standard and additional regulations. The basic method of evaluation of the microbiological status of the product is the microscopic. The method is subjective and requires significant time for preparation and evaluation of the samples. Accuracy of diagnosis is not high and depends largely on the qualifications of the expert. These are the reasons to seek ways to partially or fully automate the process of monitoring and evaluation of production using more advanced methods. Such that mimic the visual assessment of the expert - based on analysis of digital images. The use of methods for image processing requiring a long time for a decision, and based on a large volume of computational procedures, is impractical in consideration tasks.

In the selection of an appropriate algorithm of recognition the main criteria to be observed are relevance, effectiveness and time, high enough accuracy. The method for segmentation by template matching is chosen because when searching and comparison with reference objects in the image, the process is not affected by its location. An advantage of the method is that it is resistant to noise and faster than other methods of identification.

A comparative analysis is made of the more famous and accessible algorithms for segmentation by template matching in terms of their fast response and basic functions used for comparison. Besides the basic methods in practice are used variants thereof or a combination of different methods. Especially importance in recognition algorithms from a template is the problem with the use of nested loops. The number of operations performed visibly does not affect other characteristics of the algorithm. This is proven by analyzing the execution time of various algorithms. From the study it is found that in addition to the elements of the algorithms on their operation affects the size of the template used. 


\section{ACKNOWLEDGEMENTS}

This work was partially supported by research project granted by Faculty of "Technics and Technology" - Yambol, Bulgaria. 3.FTT/30.05.2016: "Contactless methods for evaluation of main quality characteristics of dairy products".

\section{REFERENCES}

[1] Alsaade F., Fast and accurate template matching algorithm based on image pyramid and sum of absolute difference similarity measure, Research Journal of Information technology, vol.4, No.4, pp.204-211, 2012 ISSN 1815-7432, DOI: 10,3923/rjit.2012.204.2112012, Academic Journal Inc.

[2] Bachelor B. G. (1985). Lighting and viewing techniques in automated visual inspection. Bedford, UK: IFSPublica tion Ltd.

[3] Barni M., V. Cappellini, A. Mecocci, (1997). Colour based detection of defects on chicken meat. Image and Vision Computing, 15, 549-556.

[4] Chmiel M., M. Slowinski, K. Dasiewicz, Lightness of the color measured by computer image analysis as a factor for assessing the quality of pork meat, Meat Science Volume 88, Issue 3, July 2011, Pages 566-570.

[5] Dawoud N., B. Samir, J. Janier, Fast Template Matching Method Based Optimized Sum of Absolute Difference Algorithm for Face Localization" International Journal of Computer Applications (0975-8887) Vol.18, No.8, March 2011.

[6] Desai B. K, M. Pandya, Dr. M. B.Potdar, Comparison of Various Template Matching Techniques for Face Recognition, International Journal of Engineering Research and Development e-ISSN: 2278-067X, www.ijerd.com, Vol. 8, Iss. 10 (October 2013), pp.1618.

[7] Elshenawy M. A., Automatic detection and identification of cells in digital images of day 2 IVF embryos, PhD Thesis, School of Computing, Science and Engineering University of Salford, Salford, UK, 2012.

[8] Fouda Y. M., One-Dimensional Vector based Pattern Matching, Submitted 10 Sep 2014 to Computer Vision and Pattern Recognition [cs.CV], Published 11 Sep 2014, http://arxiv.org/abs/1409.3024 (available on 14.07.2016).

[9] Georgieva R., Characterization of strains Latstobatsilus plantarum with probiotic properties-basis for the creation of functional foods, PhD Thesis, Sofia, 2010 (in Bulgarian).

[10] Gupta P., G. N. Purohit, M. Rathore, Number Plate Extraction using Template Matching Technique, International Journal of Computer Applications (0975-8887), Vol. 88 - No.3, February 2014, pp.40-44.

[11] Joglekar J., S. S. Gedam, Area Based Image Matching Methods - A Survey, International Journal of Emerging Technology and Advanced Engineering, Website: www.ijetae.com, ISSN 2250-2459, Volume 2, Issue 1, January 2012, pp.130-136.

[12] Kothari S., Q. Chaudry, and M. D. Wang, Automated cell counting and cluster segmentation using concavity detection and ellipse fitting techniques," in Proc. IEEE Int. Symp. Biomedical Imaging: From Nano to Macro, 2009, pp.795-798.

[13] MathWorks File Exchange, https://www.mathworks.com/matlabcentral/fileexchange (available on 12.05.2016).

[14] Mikhail I. A., Faster image template matching in the sum of the absolute value of differences measures. IEEE Trans. Image Processing, vol. 10, No2, 2001, pp.659-663. 


\section{ARTIIE Ipplied Researrches in Technicis, Technologies ind Educiation Journal of the Faculty of Technics and Technologies, Trakia University https://sites.google.com/a/trakia-uni.bg/artte/}

[15] Miroslaw L., A. Chorazyczewski, F. Buchholz, R. Kittler, Correlation-based Method for Automatic Mitotic Cell Detection in Phase Contrast Microscopy, in Computer Recognition Systems, 2005.

[16] Mladenov, M., S. Penchev, M. Deyanov, Complex assessment of food products quality using analysis of visual images, spectrophotometric and hyperspectral characteristics. International Journal of Engineering and Innovative Technology (IJEIT), Vol. 4, Iss. 12, June 2015, ISSN: 2277-3754, pp.23-32.

[17] Perveen N., D. Kumar, I. Bhardwaj, An Overview on Template Matching Methodologies and its Applications, International Journal of Research in Computer and Communication Technology, Vol 2, Issue 10, October- 2013, ISSN 2278-5841, pp.988-995.

[18] Saravanan C., M. Surender, Algorithm for Face Matching Using Normalized CrossCorrelation, International Journal of Engineering and Advanced Technology (IJEAT) ISSN: 2249-8958, Vol.2, Iss.4, April 2013.

[19] Science Direct, http://www.sciencedirect.com/ (available on 19.07.2016).

[20] Shimada T., K. Kato, A. Kamikouchi, and K. Ito, Analysis of the distribution of the brain cells of the fruit fly by an automatic cell counting algorithm," Physica A, vol. 350, pp.144149, 2005.

[21] Shivacheva G., V. Nedeva, Modern aspects of training in programming with virtual laboratory, Education and research in the information society. Proceedings of the National Conference (Plovdiv 26-27 May 2016). ISSN 1314-0752, pp. 197-206 (in Bulgarian).

[22] Stack Overflow, http://stackoverflow.com/ (available on 12.05.2016).

[23] Starter cultures, http://www.kiselomliako.bg/ (available on 12.04.2016), (in Bulgarian).

[24] Tyanev D., Yu. Petkova, A new method for important point extraction, Proceedings of the International Conference on Computer Systems and Technologies ComSysTech'2004, Ruse, Bulgaria, 17-19 June, 2004, pp. IIIA.11-1-IIIA.11-8.

[25] Vishwanathan S., Basic Principles of Algorithm Design, https://www.cse.iitb.ac.in/ cs601/Lectures/lec4.pdf (available on 15.03.2016).

[26] Young D., C.A. Glasbey, A.J. Gray, N.J. Martin, Cell identification in Differential Interference Contrast microscope images using template matching.

[27] Zlatev Z., A. Dimitrova, V. Simeonova, Selection of shape features for recognition of bacteria of the genus lactobacillus, ARTEE, Journal of Faculty of technics and Technologies, Trakia University, Vol3, No2, pp192-206, 2015, ISSN 1314-8796.

[28] Zlateva Y., Computer vision, Rousse, 2010. 